\title{
Atmospheric occurrence and health risks of PCDD/Fs, polychlorinated biphenyls, and polychlorinated naphthalenes by air inhalation in metallurgical plants
}

\author{
Lili Yang, Guorui Liu*, Minghui Zheng, Rong Jin, Qingqing Zhu, Yuyang Zhao, Xian Zhang, Yang Xu \\ State Key Laboratory of Environmental Chemistry and Ecotoxicology, Research Center for Eco-Environmental Sciences, Chinese Academy of Sciences, P.O. Box 2871, Beijing 100085, China
} University of Chinese Academy of Sciences, Beijing 100049, China

\section{H I G H L I G H T S}

- Health risks of POPs in air samples in 16 metallurgical plants were evaluated.

- The estimated cancer risks were over $10^{-4}$ for three secondary nonferrous smelters.

- PCDD/F, PCB and PCN profiles between air and stack gas samples were similar.

- Influence of stack gas emissions on surrounding air and human health was suggested.

\section{G R A P H I C A L A B S T R A C T}

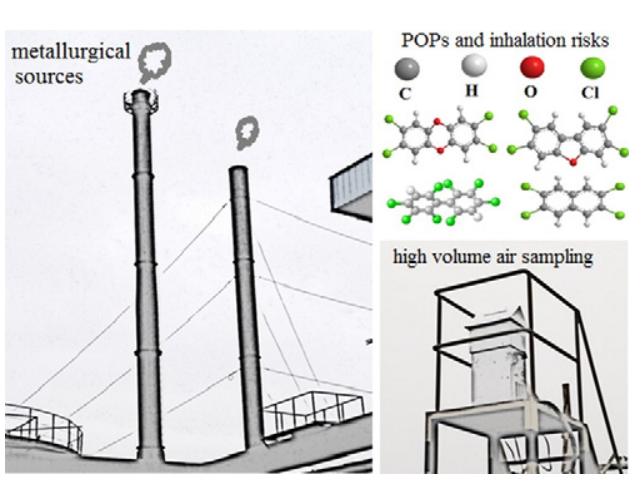

\section{A R T I C L E I N F O}

\section{Article history:}

Received 12 November 2016

Received in revised form 11 December 2016

Accepted 12 December 2016

Available online 16 December 2016

Editor: D. Barcelo

\section{Keywords:}

Persistent organic pollutants

Polychlorinated dibenzo-p-dioxins and dibenzofurans (PCDD/Fs)

Polychlorinated biphenyls (PCBs)

Polychlorinated naphthalenes (PCNs)

Metallurgical sources

Inhalation risk

\begin{abstract}
A B S T R A C T
Metallurgical plants are important sources of polychlorinated dibenzo-p-dioxins and dibenzofurans (PCDD/Fs), polychlorinated biphenyls (PCBs) and polychlorinated naphthalenes (PCNs). It is significant to evaluate the air levels and human risks of PCDD/Fs, PCBs and PCNs in metallurgical plants considering their adverse effects on human health and thousands of metallurgical plants being in operation in China. The estimated inhalation intakes of PCDD/Fs, PCBs, and PCNs together in eight iron ore sintering plants, three secondary copper plants, four secondary aluminum plants, and one secondary lead plant were 4.9-213.4, 21.4-4026.4, 28.7-630, and $11.7 \mathrm{fg}$ TEQ $\mathrm{kg}^{-1} \mathrm{day}^{-1}$, respectively, and the corresponding cancer risks were estimated to be $8.7 \times 10^{-7}$ to $3.8 \times$ $10^{-5}, 5.1 \times 10^{-6}$ to $1.1 \times 10^{-4}, 3.8 \times 10^{-6}$ to $7.1 \times 10^{-4}$, and $2.1 \times 10^{-6}$, respectively. The estimated cancer risk were higher than 100 per million people for three secondary aluminum and copper smelters among the sixteen metallurgical plants, indicating high cancer risks. Stack gas samples from metallurgical plants were also collected and analyzed for comparing their emission profiles with that of air samples. The comparison of PCDD/F, PCB and PCN profiles between air samples and stack gas samples by similarity calculation and principal component analysis suggested the influence of stack gas emissions from metallurgical plants on surrounding air. These results are helpful for understanding the exposure risk to PCDD/Fs, PCBs and PCNs in numerous metallurgical plants being operation in China.
\end{abstract}

(c) 2016 Elsevier B.V. All rights reserved.

\footnotetext{
* Corresponding author at: Research Center for Eco-Environmental Sciences, Chinese Academy of Sciences, Shuangqing Road No. 18, Haidian District, Beijing 100085, China. E-mail address: grliu@rcees.ac.cn (G. Liu).
} 


\section{Introduction}

Persistent organic pollutants (POPs) such as polychlorinated dibenzo-p-dioxins and dibenzofurans (PCDD/Fs), polychlorinated biphenyls (PCBs), and polychlorinated naphthalenes (PCNs) are of particular concern because of their notorious persistency, bioaccumulation, and high toxicity in biological systems (Gaus et al., 2002; Gioia et al., 2011). PCBs and PCNs can be unintentionally produced along with $\mathrm{PCDD} / \mathrm{Fs}$ during industrial processes and released in stack gases, which may pose risks to human health and the environment (Weber et al., 2001). PCDD/Fs, PCBs, and PCNs are listed in Annex C of the Stockholm Convention with the aim of reducing their unintentional formation and release into the environment. Conditions favoring the formation of PCDD/Fs, PCBs, and PCNs are similar and thus significant correlations among these POPs during industrial processes have been observed (Liu et al., 2009; Pandelova et al., 2006; Weber et al., 2001). For example, it was found that dominant PCBs were formed in the same regions of the sinter strand as PCDD/Fs (Aries et al., 2006). Significant correlations between PCDD/F and PCN formation have also been reported (Liu et al., 2013b; Weber et al., 2001). Moreover, the contributions of PCNs in mass and toxic equivalent (TEQ) were reported to be significant compared with those of PCDD/Fs and PCBs in environmental and human samples (Kannan et al., 2001; Park et al., 2010). The co-formation and release of PCDD/Fs, PCBs, and PCNs and their significant correlations suggest that it is necessary to consider PCDD/Fs, PCBs and PCNs together when performing study on their assessment of environmental contamination and health risk.

Metallurgical industries such as iron ore sintering and secondary non-ferrous metal smelting have been identified as dominant PCDD/F sources in China (Li et al., 2014; Liu et al., 2013a; Liu et al., 2015a, $2015 b)$. Although studies on the formation and release of PCDD/Fs, $\mathrm{PCBs}$, and PCNs during iron ore sintering and secondary non-ferrous smelting processes have been conducted (Liu et al., 2012; Liu et al., 2013a, 2013b, 2013c; Liu et al., 2014; Liu et al., 2015a, 2015b), the inhalation and health risks of these POPs in metallurgical plants, especially for PCNs as new POPs covered under the Stockholm Convention, have received little attention. Air levels of $\mathrm{PCDD} / \mathrm{Fs}$, PCBs, and PCNs have been monitored in the smelting workshops of secondary non-ferrous smelting plants, and the exposure risks by inhalation alone exceeded the tolerable daily intake (TDI: $1-4 \mathrm{pg}$ of TEQ $/ \mathrm{kg}$ of body weight) (WHO, 1998; Hu et al., 2013; Saravia et al., 2013). The air levels of PCDD/Fs, PCBs, and PCNs in air surrounding secondary copper and aluminum metallurgical facilities have also been studied (Hu et al., 2014). The comparison of PCDD/F, PCB, and PCN patterns between stack gas emissions and ambient air suggested the potential impact of industrial source emissions on the surrounding environment (Hu et al., 2014). The results of those studies suggested the need for further risk assessment of PCDD/Fs, PCBs, and PCNs in the environment surrounding industrial sources. PCDD/Fs, PCBs, and PCNs are widely recognized to be carcinogenic to human health (Fernandes et al., 2010; Warner et al., 2011a; Zhao et al., 2009; Schifano et al., 2013). However, the cancer risks through inhalation of PCDD/Fs, PCBs, and PCNs in metallurgical plants have not been evaluated in spite of a few case studies on the estimation of PCDD/F inhalation been reported (Hu et al., 2013; Saravia et al., 2013; Mari et al., 2009).

There are hundreds of iron ore sintering plants and thousands of secondary non-ferrous smelting plants in operation in China, and these plants are distributed over most of China, as shown in Fig. 1. Considering thousands of metallurgical plants in operation, it is deemed prudent to evaluate the air levels of PCDD/Fs, PCBs, and PCNs in these metallurgical plants to better understand the potential health risks faced by the numerous workers in these plants. However, an intensive field investigation on a national scale is not feasible considering the number of industrial plants, and the high cost and physical difficulty associated with the collection and analysis of air and stack gas samples (Liu and Zheng, 2013). Therefore, this case study evaluated the levels and potential health risks of PCDD/Fs, PCBs, and PCNs in air samples collected from representative iron ore sintering plants and secondary non-ferrous smelting plants.

Simultaneous monitoring of stack gas and surrounding air is likely to be important to better understand the effects of stack gas emissions on the surrounding air, although few such studies have been performed. In this study, stack gas samples from metallurgical plants were also collected and analyzed to compare PCDD/F, PCB, and PCN profiles between air and stack gas samples, which might provide important information for better understanding the contribution of stack gas emissions to surrounding air contamination and health risks.

\section{Materials and methods}

\subsection{Metallurgical plants and sample collection}

Five typical metallurgical plants were selected: two iron ore sintering plants, two secondary aluminum smelting plants, and one secondary lead smelting plant. Basic information of these plants were shown in Table S1. Each plant was investigated to evaluate the air levels and profiles of PCDD/Fs, PCBs, and PCNs around the plant. For each plant, two ambient air samples were collected using high-volume air samplers (Echo Hi-Vol, Tecora, Milan, Italy) at a flow rate of $0.24 \mathrm{~m}^{3}$ $\mathrm{min}^{-1}$ for $24 \mathrm{~h}$ (US EPA method TO-9A). Air samples were collected in or around the yard of each metallurgical plant while the plant was in operation. Cleaned quartz fiber filters (GFF; $102 \mathrm{~mm}$ diameter, baked in muffle furnace at $450{ }^{\circ} \mathrm{C}$ for $6 \mathrm{~h}$ ) and polyurethane foam [PUF; $63 \mathrm{~mm}$ diameter, $76 \mathrm{~mm}$ length, purified by accelerated solvent extraction (ASE) with acetone and hexane] were used to gather particle phase and gas phase of the air samples, respectively. Three stack gas samples were collected for each metallurgical plant using an automatic isokinetic sampling system (Isostack Basic; Tecora). The collected samples were contained in polyethylene valve bags and were wrapped with aluminum foil. Details about the collection of air samples and stack gas samples are described in previous reports (Li et al., 2008a, 2008b; Liu et al., 2009).

\section{2. $P C D D / F, P C B$, and $P C N$ analysis}

Analyses of PCDD/F congeners in stack gas and air samples were conducted according to US EPA Methods 23 and TO-9A, respectively, with modifications. PCBs were analyzed according to US EPA Method 1668B. Analysis of PCNs was conducted using the isotopic dilution high-resolution gas chromatography/high-resolution mass spectrometry (HRGC/HRMS) method established and described in our previous studies (Hu et al., 2013; Liu et al., 2010). The extraction, cleanup, and instrumental analysis for PCDD/Fs, PCBs, and PCNs were conducted as described in our previous studies (Hu et al., 2013; Hu et al., 2014; Liu et al., 2009). Briefly, the samples were spiked with the corresponding ${ }^{13} \mathrm{C}_{12^{-}}$ labeled PCDD/F, ${ }^{13} \mathrm{C}_{12}$-labeled PCB, and ${ }^{13} \mathrm{C}_{10}$-labeled PCN analogs (tetra-octa mixture comprising ${ }^{13} \mathrm{C}_{10}-\mathrm{CN}-27,-42,-52,-67,-73$, and -75 from Cambridge Isotope Laboratories) as internal standards. The samples were Soxhlet-extracted for $24 \mathrm{~h}$ and concentrated using a rotary evaporator. After purification on a multilayer silica gel column treated with $44 \%$ (mass fraction) sulfuric acid and $33 \%$ (mass fraction) sodium hydroxide, the eluate was evaporated to about $20 \mu \mathrm{L}$ by rotary evaporation and a gentle stream of nitrogen. The corresponding ${ }^{13} \mathrm{C}_{12}$-labeled injection standards were then added before sample injection into the HRGC/HRMS for calculation of internal standard recoveries.

Identification and quantification of target compounds in the extracts were performed by HRGC/HRMS using a DB- 5 ms capillary column (60$\mathrm{m} \times 0.25-\mathrm{mm}$ i.d., 0.25- $\mu \mathrm{m}$ film thickness; Agilent). The HRMS was operated in selected-ion monitoring mode (SIM) at resolution $\geq 10,000$. Details about the procedure of HRGC/HRMS have been presented before (Liu et al., 2009; Liu et al., 2010). 


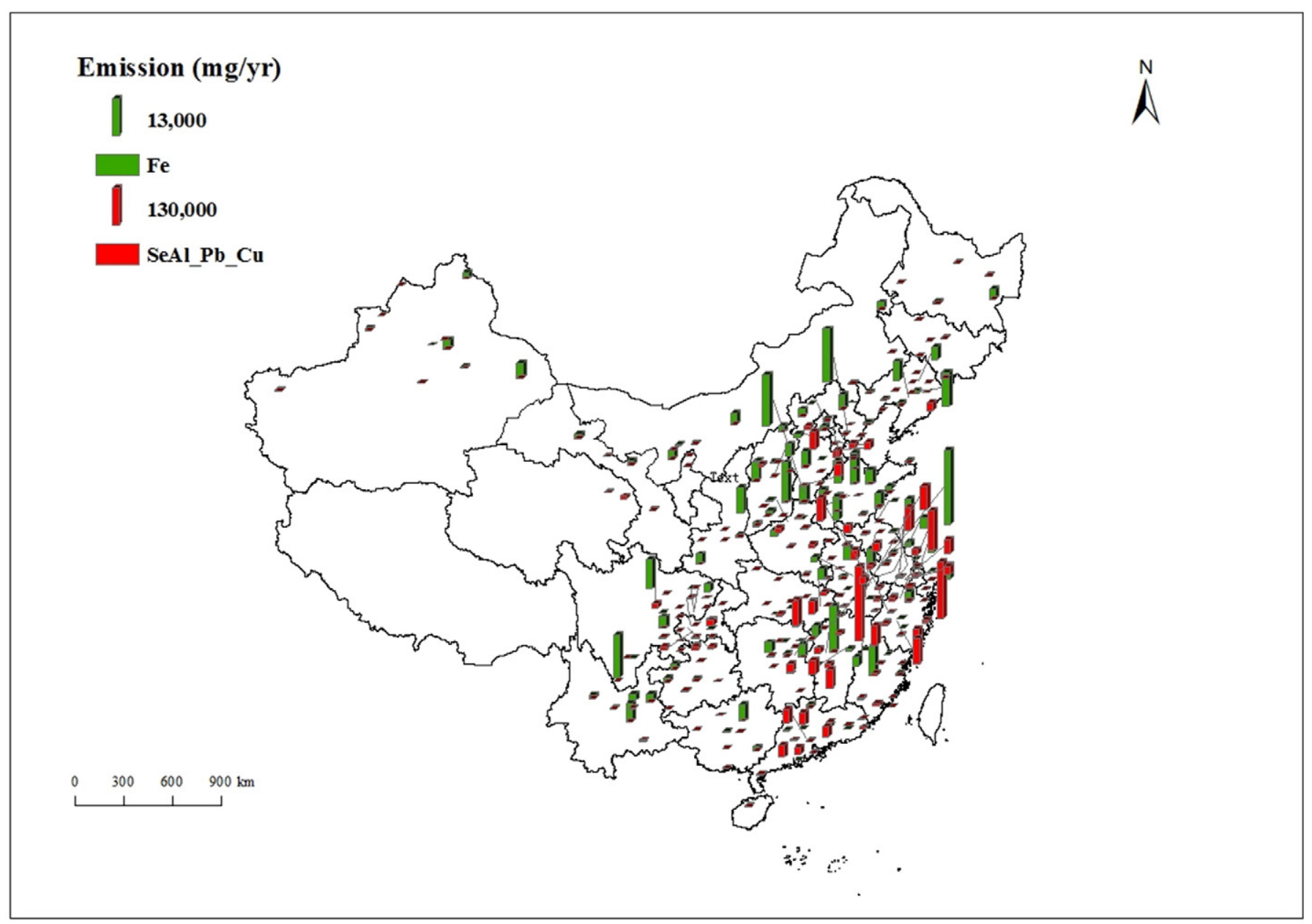

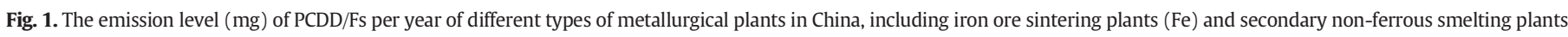
(SeAl_Pb_Cu).

The identification of the target compounds was based on the retention time and ion ratios using the corresponding ${ }^{13} \mathrm{C}$-labeled standard compounds. The internal standard recoveries of ${ }^{13} \mathrm{C}_{12}$-labeled PCDD/ Fs, ${ }^{13} \mathrm{C}_{12}$-labeled PCBs, and ${ }^{13} \mathrm{C}_{10}$-labeled PCNs $\left({ }^{13} \mathrm{C}_{10}\right.$-CN-64 from Cambridge Isotope Laboratories) in all the samples $(n=28)$ were in the range of $48.7-136.2 \%, 36.2-138.6 \%$, and $34.0-91.0 \%$, respectively. One laboratory blank was performed in each batch of samples to confirm there was no obvious contamination.

\subsection{Risk assessment}

The human exposure equation for PCDD/Fs in air was used (Nouwen et al., 2001; Tian et al., 2015):

$\operatorname{Inh}=\operatorname{VrC}_{\text {air }} f_{\mathrm{r}} t_{\mathrm{f}} / W$

where Inh is inhalation exposure (fg TEQ $\mathrm{kg}^{-1} \mathrm{day}^{-1}$ ); $\mathrm{Vr}$ is ventilation rate $\left(20 \mathrm{~m}^{3}\right.$ day $\left.^{-1}\right) ; C_{\text {air }}$ is the ambient air concentration $\left(\right.$ fg TEQ $\left.\mathrm{m}^{-3}\right)$; $f_{\mathrm{r}}$ is the alveolar fraction retained in lung $(0.75) ; t_{\mathrm{f}}$ is the exposed time fraction, assuming that individuals are exposed to the air $24 \mathrm{~h} \mathrm{day}^{-1}$ and the indoor air exposure is equal to the outdoor air exposure (assumed to be 1 for the workers); $W$ is the body weight, set at $70 \mathrm{~kg}$ for an adult (Nouwen et al., 2001; Tian et al., 2015).

Inhalation unit risk (IUR) is a quantitative indication of the carcinogenicity of a substance and an estimate of theoretical increases in cancer cases in a population expressed in concentration units $\left[\left(\mu \mathrm{g} / \mathrm{m}^{3}\right)^{-1}\right]$ (ATSDR, 2005). The values of IUR are usually derived from animal experiments that involve exposures to a single substance by a single route of exposure (i.e., ingestion or inhalation) or epidemiology studies. Currently, the inhalation unit risk (IUR) values for PCNs and PCBs are not available because of inadequate epidemiological and toxicological data for their specific congeners. Thus, the cancer risks of PCNs and PCBs were evaluated by calculating their toxic equivalents (TEQs) relative to 2,3,7,8-tetrachlorodibenzo-p-dioxin (2,3,7,8-TCDD) in this study. The carcinogenic risks of PCDD/F, PCB, and PCN inhalation were evaluated and calculated as follows. The TEQs of PCDD/Fs and PCBs were calculated by multiplying mass concentrations of individual $\mathrm{PCDD} / \mathrm{F}$ and $\mathrm{PCB}$ congeners in the ambient air by their WHO toxic equivalence factors (TEFs) 2005 (Trnovec et al., 2013; Van den Berg et al., 2006). Correspondingly, the relative potency factors (RPFs) of individual PCN congeners relative to 2,3,7,8-TCDD were listed in Table S2 have been evaluated and summarized (Blankenship et al., 2000; Noma et al., 2004; Villeneuve et al., 2000), thus allowing the calculation of PCN TEQ relative to 2,3,7,8-TCDD. The sum of TEQs of PCDD/Fs, PCBs, and PCNs in the ambient air samples was then multiplied by the IUR of $2,3,7,8-\mathrm{TCDD}\left[38\left(\mu \mathrm{g} / \mathrm{m}^{3}\right)^{-1}\right]$ as an estimate of cancer risk by air inhalation (USEPA, 2016).

\section{Results and discussion}

\section{1. $P C D D / F, P C B$, and $P C N$ concentrations and profiles}

Quantifying the levels of PCDD/Fs, PCBs, and PCNs is the primary step toward understanding the contamination status and estimating the potential health risks. The $\sum 2,3,7,8-\mathrm{PCDD} / \mathrm{F}, \sum$ dioxin-like $(\mathrm{dl})$ $\mathrm{PCB}$, and $\sum \mathrm{dl}-\mathrm{PCN}$ concentrations in the ambient air around the 
investigated metallurgical plants are presented in Table S3. We previously reported the PCDD/F, PCB, and PCN concentrations in air samples from 11 metallurgical plants (Hu et al., 2014; Li et al., 2015). However, inhalation and cancer risks were not assessed in those studies. Therefore, the current study also considers the data from these earlier studies to estimate the inhalation and cancer risks of PCDD/Fs, PCBs, and PCNs. Therefore, totally 16 metallurgical plants including eight iron ore sintering plants and eight secondary nonferrous smelting plants were included for evaluating the inhalation and cancer risk assessment in this study (Table S1). The geomean concentration in air samples from secondary copper smelting processes was $1787.2 \mathrm{fg}$ WHO-TEQ $\mathrm{Nm}^{-3}$ (range: 100.0-18,790.0 fg WHO-TEQ $\mathrm{Nm}^{-3}, n=9$ ), which was higher than that for secondary aluminum smelters (geomean: $557.1 \mathrm{fg}$ WHOTEQ $\mathrm{Nm}^{-3}$, range: $133.9-2940.0$ fg WHO-TEQ $\mathrm{Nm}^{-3}, n=10$ ), iron ore sintering plants (geomean: 241.2 fg WHO-TEQ $\mathrm{Nm}^{-3}$, range: $23-$ 995.7 fg WHO-TEQ $\mathrm{Nm}^{-3}, n=15$ ), and secondary lead smelting plants (geomean: 54.6 fg WHO-TEQ $\mathrm{Nm}^{-3}$, range: 52.3-57.0 fg WHO-TEQ $\mathrm{Nm}^{-3}, n=2$ ). The mass concentrations of PCN homologs were higher than those of PCDD/Fs and PCBs in the air samples, even though its TEQ share was the lowest. PCDFs were the biggest contributor to the total TEQ and accounted for about $79.4 \%$ of total TEQs of PCDD/Fs, PCBs, and PCNs (Fig. S1).

To illustrate the PCDD/F, PCB, and PCN distributions in the ambient air samples from the investigated metallurgical plants, the congeners and homologs were normalized to their respective total concentrations. The PCDD/F, PCB, and PCN congener profiles in the ambient air samples from the metallurgical plants were quite similar. As shown in Fig. 2, higher chlorinated congeners such as octachlorodibenzofuran (OCDF), 1,2,3,4,6,7,8-heptachlorodibenzofuran (HpCDF), octachlorodibenzodioxin (OCDD), and 1,2,3,4,6,7,8heptachlorodibenzo-p-dioxin (HpCDD) dominated PCDD/F profiles, and made relative contributions of $16.2 \pm 4.9 \%, 15.4 \pm 1.2 \%, 16.6 \pm$ $4.4 \%$, and $10.9 \pm 3.4 \%$, respectively. CB-77 was the main dl-PCB congener, especially for the secondary lead smelting plants (about $86.4 \%$ of dl-PCBs), followed by CB-118, CB-105, and CB-126. Lower chlorinated PCN congeners, such as $\mathrm{CN}-2, \mathrm{CN}-1, \mathrm{CN}-10, \mathrm{CN}-4$, and $\mathrm{CN}-5 / 7$, were the dominant PCN congeners.

Stack gas samples were also collected and analyzed for PCDD/Fs, PCBs, and PCNs to compare their profiles with those of air samples. $\sum$ 2378-PCDD/F, $\sum$ dl-PCB, and $\sum$ dl-PCN concentrations in the stack gas from metallurgical plants were $0.9-154.9 \mathrm{ng} \mathrm{Nm}^{-3}(0.02-1.9 \mathrm{ng}$ WHO-TEQ $\mathrm{Nm}^{-3}$ ), 0.2-7.1 $\mathrm{ng} \mathrm{N} \mathrm{m} \mathrm{N}^{-3}$ (0.001-0.1 ng WHO-TEQ $\mathrm{Nm}^{-3}$ ), and 11.4-393.8 $\mathrm{ng} \mathrm{Nm}^{-3}\left(0.1-1.3 \mathrm{ng} \mathrm{TEQ} \mathrm{Nm}^{-3}\right)$, respectively. As shown in Fig. S2, the relative concentrations of different POPs in various industrial processes displayed the same trends except for PCN emissions in secondary lead smelters. The proportions of PCDFs, PCDDs, dl-PCBs, and PCNs contributing to the total TEQs were $81.2 \%$, $14.7 \%, 4.1 \%$, and $0.06 \%$, respectively, which indicated that PCDD/Fs as the dominant TEQ contributors were still the priority controlled unintentional POPs.

The distribution patterns of 17 2,3,7,8-PCDD/F, $12 \mathrm{dl}-\mathrm{PCB}$, and $18 \mathrm{dl}-$ PCN congeners in stack gas samples are presented in Fig. S3. The results show that the dominant congeners of PCDD/Fs, dl-PCBs, and dl-PCNs in the stack gas samples were the same as those in the ambient air. The $\mathrm{PCDD} / \mathrm{F}, \mathrm{PCB}$, and PCN distribution patterns from iron ore sintering plants and secondary non-ferrous smelting plants were generally similar. However, the PCDD/F homolog profiles in stack gas samples from secondary lead smelting plants were different from those of other metallurgical plants. Higher chlorinated homologs comprising hexachlorodibenzofuran (HxCDF), HpCDF, OCDF, and HpCDD were the dominant PCDD/F homologs in the stack gas samples, except for secondary lead smelters. As the level of chlorination increased, the homolog concentrations of PCDD/Fs decreased in the stack gas samples from secondary lead smelters. The lower chlorinated PCBs, such as dichlorinated, trichlorinated, and tetrachlorinated biphenyls, were the dominant PCBs in the stack gas samples and accounted for $86.5-99.5 \%$ of the total PCBs.
For PCNs, the lower chlorinated homologs, such as monochlorinated, dichlorinated, and trichlorinated naphthalenes, were also dominant and accounted for $84.8-99.9 \%$ of the total PCNs.

Normalization can be used to minimize the influence of different homolog concentrations and make the fingerprints of POPs from metallurgical plants more comparable (Fiedler et al., 1996). Therefore, the concentration of each 2,3,7,8-PCDD/F, dl-PCB, and dl-PCN congener was divided by the concentration of the corresponding homolog (same degree of chlorination). The result showed that 2,3,7,8-PCDD/F, $\mathrm{dl}-\mathrm{PCB}$, and dl-PCN fingerprints from iron ore sintering plants and secondary non-ferrous smelting plants were quite different, especially for PCBs and PCNs, even though similar variation trends were observed (see Fig. S4). These specific isomer patterns can be helpful for identifying the specific sources of PCDD/Fs, PCBs, and PCNs in the air samples.

\subsection{Comparison of $P C D D / F, P C B$, and $P C N$ profiles between ambient air and stack gas emissions}

Homolog and congener profiles of PCDD/Fs, PCBs, and PCNs were adopted to compare their distributions in ambient air and stack emission gas from metallurgical industries. As shown in Fig. 3, homolog concentrations of PCDFs in both the stack gas and ambient air were higher than the corresponding homolog concentrations of PCDDs. For PCDD/F homolog profiles, lower chlorinated PCDD/Fs (tetra-, penta-, and hexa-) were the main homologs in the ambient air from the metallurgical plants, and the homolog concentrations decreased with the increasing degree of chlorination. For PCDD/F homolog profiles in the stack gas, higher chlorinated PCDD/Fs were the main homologs. The different PCDD/F homolog profiles between stack gas emissions and air samples may be attributed to the different transport behaviors of PCDD/F homologs. As shown in Fig. S5, higher chlorinated PCDD/F homologs were more easily attached to particulates than that of lower chlorinated homologs, which making higher chlorinate homologs cannot spread freely and tend to be deposited around the industrial sources. Therefore, the lower chlorinated homologs detected in the ambient air samples were more abundant than in the stack gas. PCNs and PCBs much more tended to distribute in the gas phase than that of PCDD/Fs. For PCB and PCN homolog profiles, the lower chlorinated PCBs and PCNs were the dominant homologs for both ambient air and stack gas, and the concentration proportion of the total decreased with the increasing degree of chlorination.

Homolog profiles may change considerably during transfer from the emission source to the surrounding air because of the difference in chlorine numbers on the molecular skeletons of the different homologs (Fiedler et al., 1996). Considering that congeners with the same degree of chlorination would be affected in the same way, the congener patterns normalized to their respective homologs were more stable than homolog profiles and thus much more specific than homolog profiles (Fiedler et al., 1996). Therefore, to identify the possible influence of industrial sources on the surrounding ambient air, the normalization method (concentration of each 2,3,7,8-PCDD/F, dl-PCB, and dl-PCN congener was divided by the concentration of their corresponding homo$\log$ ) was adopted to make concentration data for air and stack gas samples more comparable. As shown in Fig. 4, for PCDD/Fs, the curves almost coinciding for the air and stack gas samples for the three kinds of metallurgical plants, indicating the significant influence of stack gas emissions on the surrounding air.

Similarity $(S)$, shown as follows, is also used to evaluate the matching of congener patterns:

$$
s=\frac{\sum A_{i} B_{i}}{\sqrt{\sum\left(A_{i}\right)^{2} \sum\left(B_{i}\right)^{2}}}
$$

where $A_{i}$ and $B_{i}$ are the normalized contents of the congener $i$ in sample A and B, respectively (Liu et al., 2015a, 2015b). The similarities of PCDD/ 

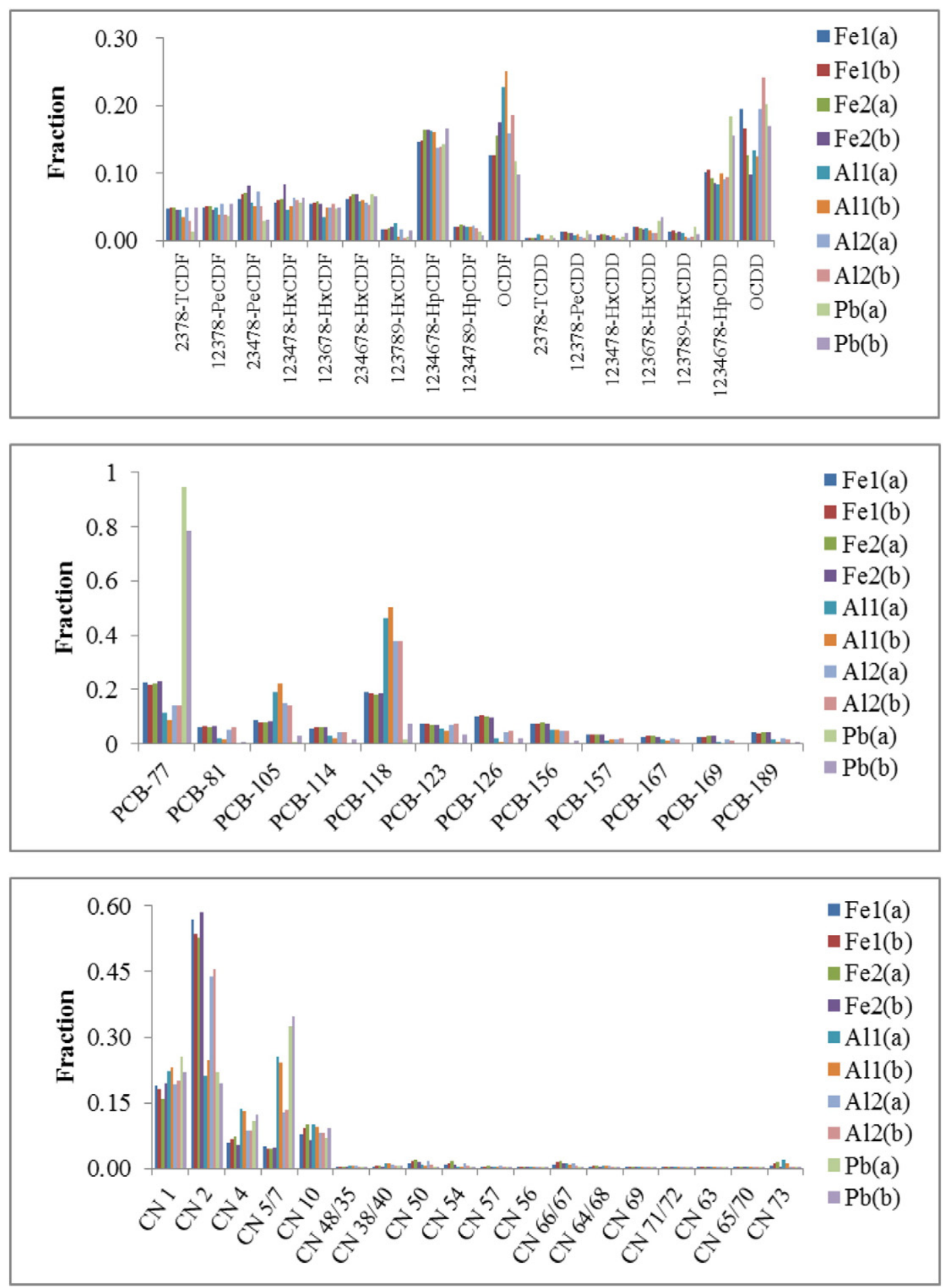

Fig. 2. Congener profiles of PCDD/Fs, dl-PCBs, and dl-PCNs in the ambient air samples from metallurgical plants.

F congener fractions between the air and stack gas samples from different kinds of metallurgical plants were 92.6-98.8\%, which further suggested an underlying connection of PCDD/Fs between air and stack gas samples. It can be inferred that the PCDD/Fs in the air surrounding metallurgical plants come mainly from the surrounding industrial sources. Principal component analysis (PCA) could summarize the original information in a reduced number of new orthogonal variables to assess the main variability in the data matrix, which can also facilitate the recognition of patterns in the sample distribution according their similarity and difference. A rotation method using Varimax with Kaiser Normalization was adopted in the PCA (Rocha et al., 2016). In this study, PCA was also applied to identify possible factors responsible for PCDD/Fs, PCBs, and PCNs in the air. The result showed that only one component accounting for about $97 \%$ of the variability of the dataset was extracted for PCDD/Fs, which indicated that the surrounding industrial sources are the dominant factor influencing the PCDD/F concentrations in the air around the metallurgical plants.

For PCBs, a small part of the ratios of congeners to corresponding homologs overlapped, even though the general tendency of function was similar (see Fig. 4). The similarity of PCB congener fractions between 


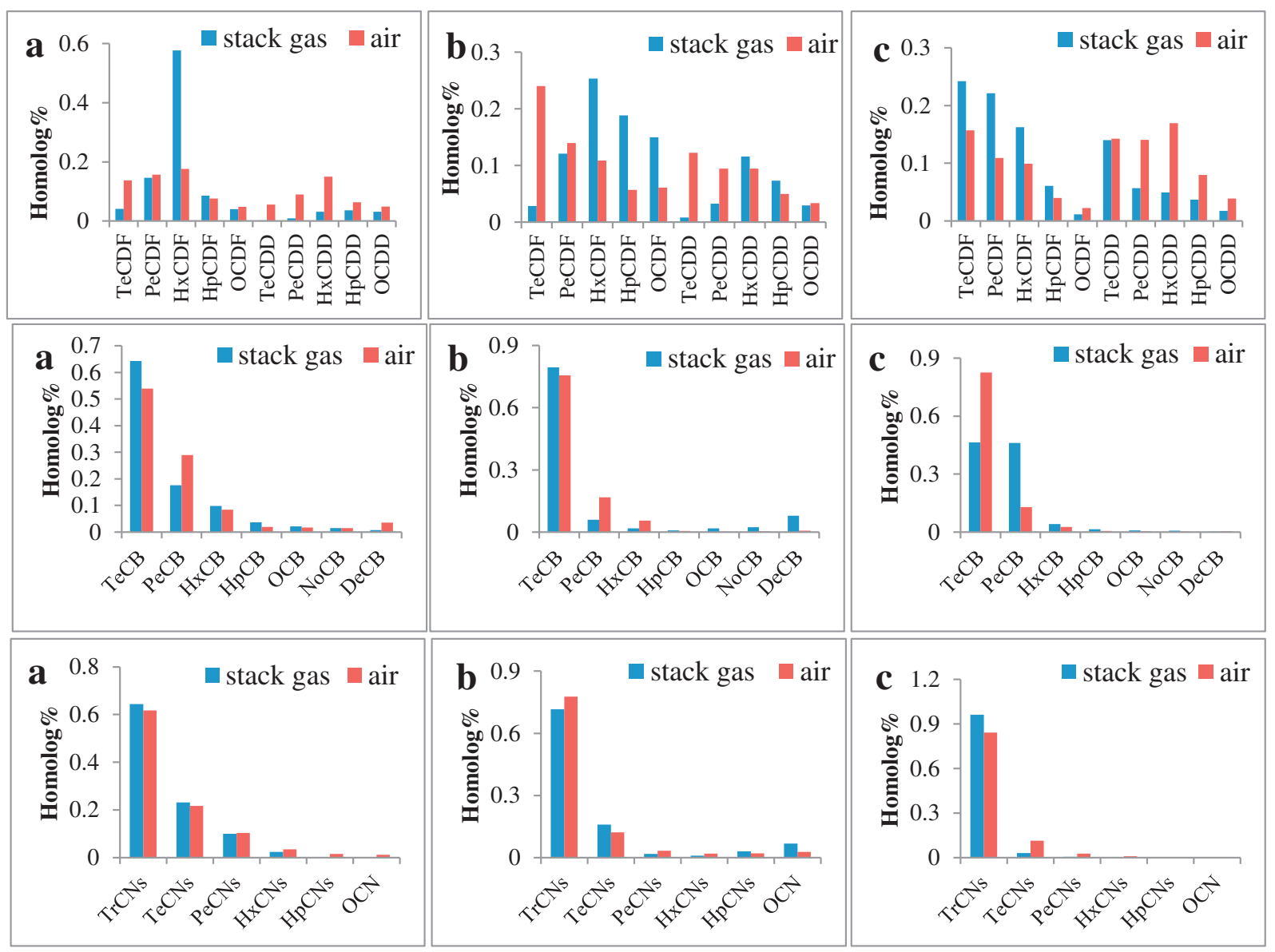

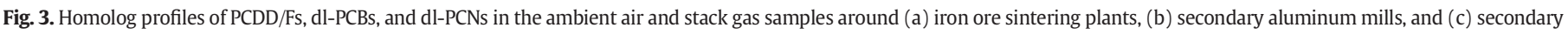
lead mills.

the air and stack gas samples was 63.9-92.3\%, which is somewhat lower than that of PCDD/Fs. Moreover, the score plot of PCA showed the three components responsible for the variability of the dataset (see Fig. S6). The first component accounted for about $70 \%$ of the variability of the dataset, and was mainly determined by higher chlorinated PCB homologs. The score plot of PCBs in Fig. S6 showed that air samples cannot be completely separated from stack gas samples, which indicates that PCB occurrence in the ambient air around the plants might be partially influenced by nearby industrial sources. Therefore, it can be generally inferred that PCBs in the air around the metallurgical plants might be affected by not only the unintentional industrial sources, but also by other sources such as technical PCB mixtures used in capacitors and transformers, or as impurities in pigments and dyes (Breivik et al., 2007; Davies and Delistraty, 2016).

For PCNs, the score plot of the PCA showed that the first component responsible for $61 \%$ of the variability of the dataset was mainly influenced by higher chlorinated PCNs (penta- to hepta-) in the positive direction (Fig. S6). The samples from the different industrial sources can be divided into two clusters: the first on the right (Cluster A) includes samples from the iron ore sintering plants and the secondary aluminum smelting plants; and the second on the left (Cluster B) includes samples from the secondary aluminum and lead smelting plants. However, there was no clear distinction between stack gas and ambient air samples from different sources in the score plot of the PCA, which indicated that PCN concentrations in the ambient air may be influenced by the interaction of stack gas from different plants. The ratios of PCN congeners to their corresponding homologs in the surrounding air was almost consistent with that of the stack gas from the iron ore sintering plants and the secondary aluminum plants (similarity: 95.7-98.3\%), and was higher than that of the secondary lead plant ( similarity: 87.9\%). Furthermore, curves of PCN congener fraction in all the air samples from different metallurgical plants were almost the same, with similarities ranging from 91.1 to $95.7 \%$, except for $\mathrm{CN}-5 / 7$ (68.7\%). These findings suggest that PCNs in the surrounding air were mainly affected by the mixture of stack gases from different industrial plants in the industrial park because of the relatively high vapor pressure and the fast transmission properties of PCNs in air.

Generally, PCDD/F levels in the ambient air may be significantly affected by industrial point sources, while the PCN level would be influenced by the interaction of stack gases from different industrial sources. PCBs in the ambient air may not only be influenced by the unintentional industrial sources, but also by other intentional sources.

\subsection{Assessment of inhalation and cancer risk of PCDD/Fs, PCBs, and PCNs in metallurgical plants}

Considering the hundreds of thousands of metallurgical plants in operation in China, it is logical to evaluate the inhalation of PCDD/Fs, PCBs, and PCNs in those metallurgical plants to better understand the potential health risks faced by the numerous workers in the metallurgical plants. Although a few publications have reported the inhalation of unintentional POPs, those studies mainly focused on urban atmospheres (Li et al., 2008a, 2008b; Li et al., 2011; Tian et al., 2015; Yu et al., 2006). Moreover, only inhalation of PCDD/Fs in urban air was emphasized in those studies (Domingo et al., 2002; Karademir, 2004; Lee et al., 2007; Shih et al., 2008). The inhalation of dioxin-like compounds, especially for PCNs, has been scarcely reported up to now. 


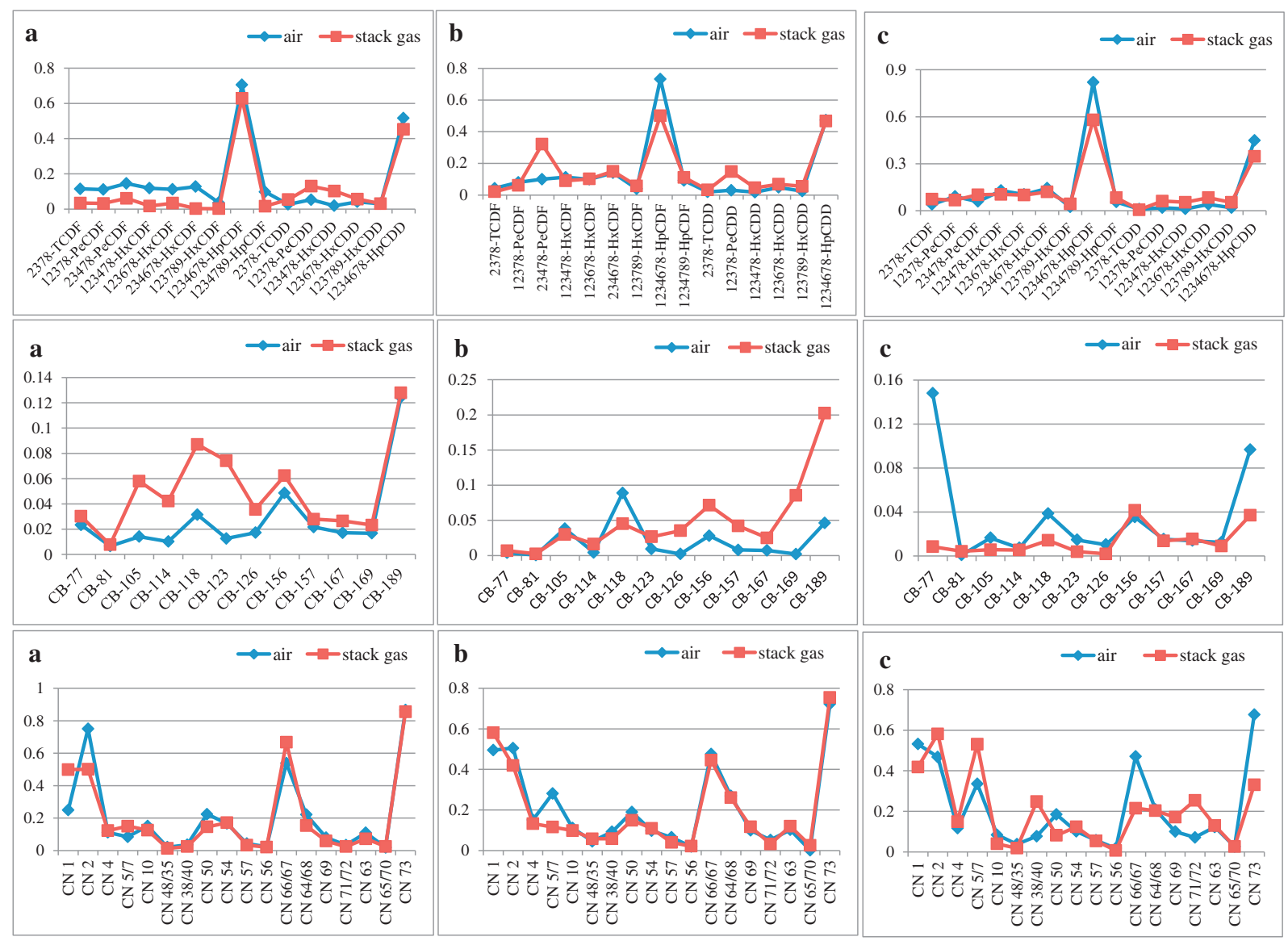

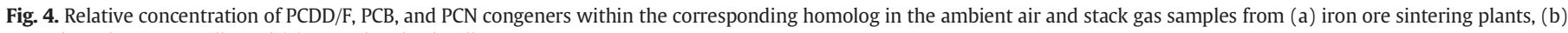
secondary aluminum mills, and (c) secondary lead mills.

In this study, the inhalation of PCDD/Fs, PCBs, and PCNs in 16 metallurgical plants was calculated based on their TEQ concentrations. The average inhalation level of PCDD/Fs, PCBs, and PCNs in eight iron ore sintering plants was $85.1 \mathrm{fg}$ TEQ $\mathrm{kg}^{-1} \mathrm{day}^{-1}$ (range: 4.9-213.4 fg TEQ $\mathrm{kg}^{-1} \mathrm{day}^{-1}$ ). The average inhalation of PCDD/Fs, PCBs, and PCNs was $1330.7 \mathrm{fg}$ TEQ $\mathrm{kg}^{-1}$ day $^{-1}\left(21.4-4026.4 \mathrm{fg}\right.$ TEQ $\mathrm{kg}^{-1} \mathrm{day}^{-1}$ ) for the three secondary copper plants and 212.6 fg TEQ $\mathrm{kg}^{-1}$ day $^{-1}$ (28.7$630 \mathrm{fg}$ TEQ $\mathrm{kg}^{-1} \mathrm{day}^{-1}$ ) for four aluminum plants. The average inhalation of PCDD/Fs, PCBs, and PCNs for a secondary lead smelting plant was $11.7 \mathrm{fg}$ TEQ $\mathrm{kg}^{-1} \mathrm{day}^{-1}$. The inhalation risks for workers and residents downwind of the secondary copper smelters were about twice those situated upwind, further indicating the influence of source emissions on the surrounding air. The proportion of PCB contribution to the total inhalation risk in different plants differed significantly. PCB inhalation in the secondary aluminum smelting plants was calculated to be $2.2-505.7 \mathrm{fg}$ TEQ $\mathrm{kg}^{-1} \mathrm{day}^{-1}$ and took up about $37 \%$ (range: $6.3-80.6 \%$ ) of the total inhalation, which was higher than that in other metallurgical plants (1.96-18.8\%). To our knowledge, there is no report available in the literature associated with air inhalation of PCDD/Fs and PCBs in metallurgical plants, although studies of inhalation of PCDD/Fs in urban air in Guangzhou and Shanghai were reported previously (Li et al., 2008a, 2008b; Yu et al., 2006). The estimated inhalations of workers in the investigated metallurgical plants were obviously higher than those of urban residents in Guangzhou (19.7-145 fg TEQ kg ${ }^{-1}$ day $^{-1}$ ) and Shanghai (30.6-106 fg TEQ $\mathrm{kg}^{-1} \mathrm{day}^{-1}$ ) (Li et al., 2008a, 2008b; Yu et al., 2006), but were much lower than the daily intakes of residents in an electronic waste dismantling area (1.88-6.08 pg TEQ $\mathrm{kg}^{-1} \mathrm{day}^{-1}$ ) and workers in a smelting workshop that we reported previously (0.17-10.85 pg TEQ $\mathrm{kg}^{-1}$ day $^{-1}$ ) (Hu et al., 2013; Li et al., 2007).
In 2015, PCNs were included as POPs in Annexes A and C covered under the Stockholm Convention. To our knowledge, there is no available publication associated with the air inhalation risk assessment of PCNs in metallurgical plants. However, the toxic equivalent factors of individual PCN congeners relative to 2,3,7,8-TCDD have been evaluated and summarized (Blankenship et al., 2000; Noma et al., 2004; Villeneuve et al., 2000). Thus, the inhalation risk of PCNs could be evaluated in TEQs relative to 2,3,7,8-TCDD. In this study, the air inhalation of PCNs in mass burden ranged from 1.5 to $861.4 \mathrm{pg} \mathrm{kg}^{-1} \mathrm{day}^{-1}$. The inhalation of PCNs in toxic equivalents was estimated to be $0.01-135 \mathrm{fg}$ TEQ $\mathrm{kg}^{-1} \mathrm{day}^{-1}$ and took up about $0.1-10.0 \%$ of the total inhalation risk contributed by $\mathrm{PCDD} / \mathrm{F}, \mathrm{PCB}$, and $\mathrm{PCNs}$. High relative risk was noted in the secondary copper plants (1.9-135 fg TEQ $\mathrm{kg}^{-1} \mathrm{day}^{-1}$ ), and PCN inhalation in the two secondary copper plants was even higher than the $\mathrm{PCDD} / \mathrm{F}$ inhalation in four iron ore sintering plants. This indicates that PCN inhalation risks should be highlighted and included when assessing the health risks of air in metallurgical plants. Our results on PCN inhalation could be the first data used to understand the exposure of workers in metallurgical plants to PCNs in the air.

PCDD/Fs, PCBs, and PCNs are widely recognized as possible human carcinogens based on animal experiments by the International Agency for Research on Cancer (Humblet et al., 2008; Wang et al., 2013). In the current study, carcinogenic risk of PCDD/Fs, PCBs, and PCNs by air inhalation was evaluated to describe the probability of developing cancer for workers and residents around the industrial sources. As shown in Fig. 5, the inhalation cancer risk of workers to PCDD/Fs, PCBs, and PCNs together in eight iron ore sintering plants was $1.5 \times 10^{-5}$ (range: $8.7 \times$ $10^{-7}$ to $3.8 \times 10^{-5}$ ). The average cancer risk of $\mathrm{PCDD} / \mathrm{Fs}$, PCBs, and PCNs was $3.8 \times 10^{-5}$ (range: $5.1 \times 10^{-6}$ to $1.1 \times 10^{-4}$ ) for the four secondary aluminum plants, and $2.4 \times 10^{-4}$ (range: $3.8 \times 10^{-6}$ to $7.1 \times 10^{-4}$ ) for 

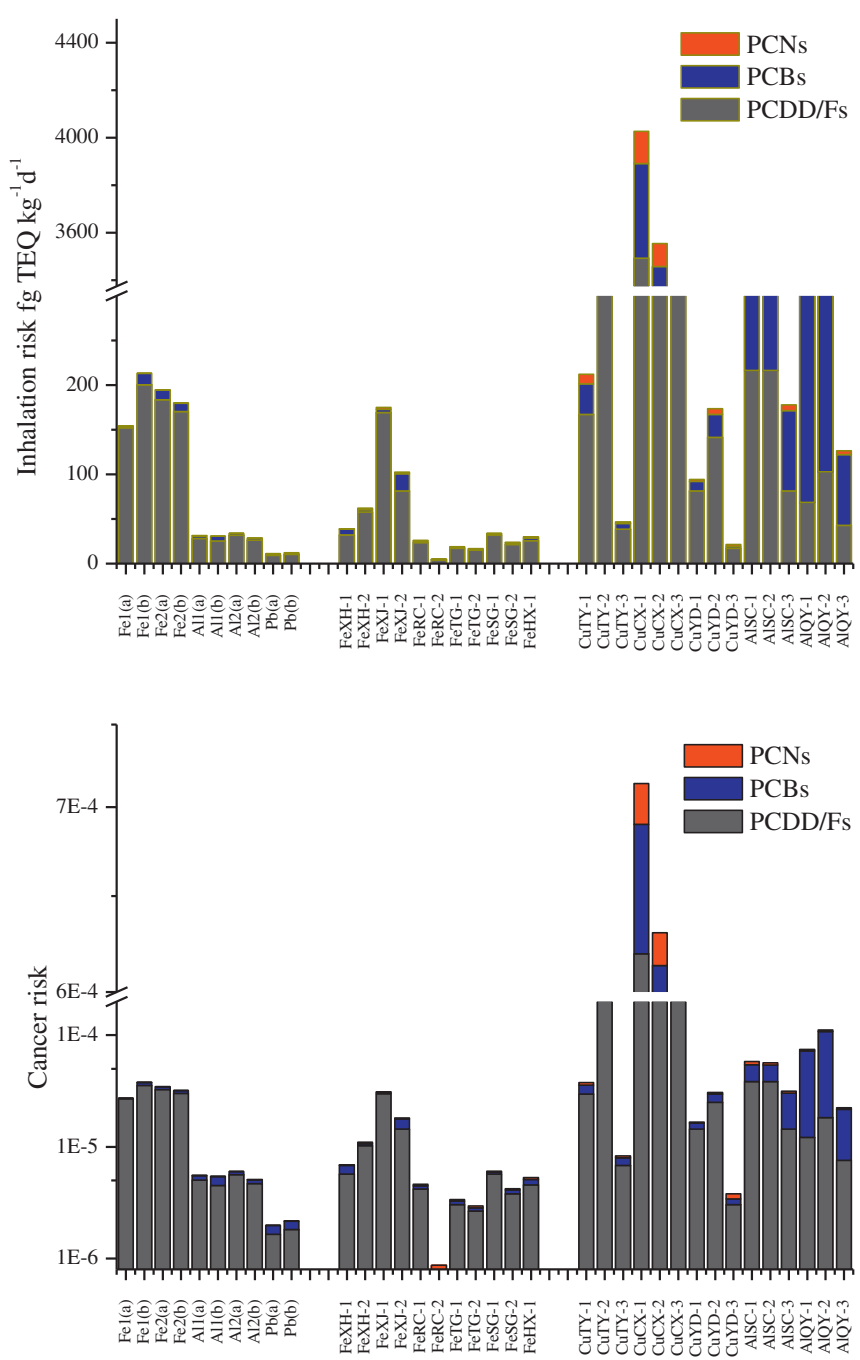

Fig. 5. Inhalation and cancer risk assessment of PCDD/Fs, PCBs, and PCNs in metallurgical plants.

the three secondary copper plants. The average cancer risk of PCDD/Fs, PCBs, and PCNs for the investigated secondary lead smelting plant was $2.1 \times 10^{-6}$. Under most regulatory programs, a value below $10^{-6}$ would be considered to pose negligible cancer risk to workers. However, values ranging from $10^{-6}$ to $10^{-4}$ pose a potential cancer risk, and values above $10^{-4}$ pose high risk (Sun et al., 2016). Thus, the workers in the metallurgical plants investigated in this study are likely to be exposed to $\mathrm{PCDD} / \mathrm{Fs}, \mathrm{PCBs}$, and PCNs in the ambient air, especially in the secondary aluminum and copper smelters at the average level of $10^{-4}$. In addition, the calculated cancer risk in the industrial sources were obviously higher than those of the urban ambient samples from Taipei $\left(1.1 \times 10^{-6}\right)$, Shanghai $\left(2.2 \times 10^{-6}\right)$, and Guangzhou $(2.5 \times$ $10^{-6}$ ) (Ho et al., 2016; Li et al., 2008a, 2008b; Li et al., 2011; Yu et al., 2006). Some reports have revealed that risks of all cancer mortality such as lung cancer and lymphatic and hematopoietic tissue cancers for residents in a dioxin-contaminated area were increased significantly compared with those in a reference area, thereby supporting the evaluation of dioxins as carcinogenic to humans (Bertazzi et al., 2001; Warner et al., 2011b). Therefore, the carcinogenic effects of PCDD/Fs, PCBs, and PCNs released from industrial sources need to be further recognized.

In recent years, human health risks of PCDD/Fs from industrial plants have attracted much more attentions than before, and some national regulations about PCDD/F emission limits have been established for reducing exposure to PCDD/Fs in China. For examples, the stack gas emission limits of PCDD/Fs have been regulated to be $0.5 \mathrm{ng} \mathrm{TEQ} / \mathrm{m}^{3}$ for new built iron ore sinters (National Standard of China: GB 28662-2012) and secondary nonferrous metal industry (National Standard of China: GB 31574-2015). However, national regulations about the PCB and PCN emissions are lacking. The atmosphere quality standards of PCDD/F, PCB and PCN concentrations in air are not available in China to our knowledge. Much more preventive measures and national regulations associated with unintentionally produced POPs from metallurgical plants might be needed for reducing potential exposure risks.

\section{Conclusion}

PCDD/F, PCB, and PCN levels in the ambient air of metallurgical plants were determined, and the related inhalation and cancer risks were estimated. This is the first report of the estimation of the inhalation and cancer risks of PCNs relative to 2,3,7,8-TCDD in the air of multiple metallurgical plants. Profiles of PCDD/Fs, PCBs, and PCNs in stack gas samples from the metallurgical plants were also determined and compared with those of the ambient air in the metallurgical plants. The isomer pattern, similarity calculations, and PCA analysis suggested the influence of stack gas emissions from the metallurgical plants on the levels of PCDD/Fs, PCBs, and PCNs in the surrounding ambient air. The results presented in this case study will be helpful in understanding the inhalation and cancer risks of PCDD/Fs, PCBs, and PCNs in the numerous metallurgical plants that are in operation in China.

\section{Acknowledgments}

This work was supported by the National Natural Science Foundation of China (91543108), the Chinese National 973 Program (2015CB453100), the Strategic Priority Research Program of the Chinese Academy of Sciences (XDB14020102), and the Youth Innovation Promotion Association of the Chinese Academy of Sciences (2016038).

\section{Appendix A. Supplementary data}

Supplementary data to this article can be found online at http://dx. doi.org/10.1016/j.scitotenv.2016.12.071.

\section{References}

Aries, E., Anderson, D.R., Fisher, R., Fray, T.A., Hemfrey, D., 2006. PCDD/F and “dioxin-like” PCB emissions from iron ore sintering plants in the UK. Chemosphere 65, 1470-1480.

ATSDR, 2005. Public Health Assessment Guidance Manual: Appendix F: Derivation of Comparison Values. https://www.atsdr.cdc.gov/hac/phamanual/appf.html.

Bertazzi, P. A. Consonni, D., Bachetti, S., Rubagotti, M., Baccarelli, A. Zocchetti, C., et al, 2001. Health effects of dioxin exposure: a 20-year mortality study. Am. J. Epidemiol. 153, 1031-1044.

Blankenship, A.L, Kannan, K, Villalobos, S.A, Villeneuve, D.L, Falandysz, J. Imagawa, T, et al., 2000. Relative potencies of individual polychlorinated naphthalenes and halowax mixtures to induce ah receptor-mediated responses. Environ. Sci. Technol. 34, 3153-3158.

Breivik, K., Sweetman, A., Pacyna, J.M., Jones, K.C., 2007. Towards a global historical emission inventory for selected PCB congeners-a mass balance approach 3. An update. Sci. Total Environ. 377, 296-307.

Davies, H., Delistraty, D., 2016. Evaluation of PCB sources and releases for identifying priorities to reduce PCBs in Washington State (USA). Environ. Sci. Pollut. R. 23, 2033-2041

Domingo, J.L., Schuhmacher, M., Agramunt, M.C., Llobet, J.M., Rivera, J., Muller, L., 2002. PCDD/F levels in the neighbourhood of a municipal solid waste incinerator after introduction of technical improvements in the facility. Environ. Int. 28, 19-27.

Fernandes, A., Mortimer, D., Gem, M., Smith, F., Rose, M., Penton, S., et al., 2010. Polychlorinated naphthalenes (PCNs): congener specific analysis, occurrence in food, and dietary exposure in the UK. Environ. Sci. Technol. 44, 3533-3538.

Fiedler, H., Lau, C., Kjeller, L.O., Rappe, C., 1996. Patterns and sources of polychlorinated dibenzo-p-dioxins and dibenzofurans found in soil and sediment samples in southern Mississippi. Chemosphere 32, 421-432.

Gaus, C., Brunskill, G.J., Connell, D.W., Prange, J., Muller, J.F., Papke, O., et al., 2002. Transformation processes, pathways, and possible sources of distinctive polychlorinated dibenzo-p-dioxin signatures in sink environments. Environ. Sci. Technol. 36, 3542-3549.

Gioia, R., Eckhardt, S., Breivik, K., Jaward, F.M., Prieto, A., Nizzetto, L., et al., 2011. Evidence for major emissions of PCBs in the West African region. Environ. Sci. Technol. 45, 1349-1355. 
Ho, C.C., Chan, C.C., Chio, C.P., Lai, Y.C., Chang-Chien, G.P., Chow, J.C., et al., 2016. Source apportionment of mass concentration and inhalation risk with long-term ambient PCDD/Fs measurements in an urban area. J. Hazard. Mater. 317, 180-187.

Hu, J., Zheng, M., Liu, W., Li, C., Nie, Z., Liu, G., et al., 2013. Occupational exposure to polychlorinated dibenzo- $p$-dioxins and dibenzofurans, dioxin-like polychlorinated biphenyls, and polychlorinated naphthalenes in workplaces of secondary nonferrous metallurgical facilities in China. Environ. Sci. Technol. 47, 7773-7779.

Hu, J., Zheng, M., Liu, W., Nie, Z., Li, C., Liu, G., et al., 2014. Characterization of polychlorinated dibenzo-p-dioxins and dibenzofurans, dioxin-like polychlorinated biphenyls, and polychlorinated naphthalenes in the environment surrounding secondary copper and aluminum metallurgical facilities in China. Environ. Pollut. 193, 6-12.

Humblet, O., Birnbaum, L., Rimm, E., Mittleman, M.A., Hauser, R., 2008. Dioxins and cardiovascular disease mortality. Environ. Health Perspect. 116, 1443-1448.

Kannan, K., Kober, J.L., Kang, Y.S., Masunaga, S., Nakanishi, J., Ostaszewski, A., et al., 2001. Polychlorinated naphthalenes, biphenyls, dibenzo-p-dioxins, and dibenzofurans as well as polycyclic aromatic hydrocarbons and alkylphenols in sediment from the Detroit and Rouge rivers, Michigan, USA. Environ. Toxicol. Chem. 20, 1878-1889.

Karademir, A., 2004. Health risk assessment of PCDD/F emissions from a hazardous and medical waste incinerator in Turkey. Environ. Int. 30, 1027-1038.

Lee, S.J., Choi, S.D., Jin, G.Z., Oh, J.E., Chang, Y.S., Shin, S.K., 2007. Assessment of PCDD/F risk after implementation of emission reduction at a MSWI. Chemosphere 68, 856-863.

Li, H., Yu, L., Sheng, G., Fu, J., Peng, P., 2007. Severe PCDD/F and PBDD/F pollution in air around an electronic waste dismantling area in China. Environ. Sci. Technol. 41, 5641-5646.

Li, H., Feng, J., Sheng, G., Lu, S., Fu, J., Peng, P., et al., 2008a. The PCDD/F and PBDD/F pollution in the ambient atmosphere of shanghai, China. Chemosphere 70, 576-583.

Li, Y.M., Jiang, G.B., Wang, Y.W., Wang, P., Zhang, Q.H., 2008b. Concentrations, profiles and gas-particle partitioning of PCDD/Fs, PCBs and PBDEs in the ambient air of an e-waste dismantling area, Southeast China. Chin. Sci. Bull. 53, 521-528.

Li, H., Zhou, L., Mo, L., Peng, P., Sheng, G., Fu, J., et al., 2011. Levels and congener profiles of particle-bound polybrominated dibenzo-p-dioxins/furans (PBDD/Fs) in ambient air around Guangzhou, China. Bull. Environ. Contam. Toxicol. 87, 184-189.

Li, S., Zheng, M., Liu, W., Liu, G., Xiao, K., Li, C., 2014. Estimation and characterization of unintentionally produced persistent organic pollutant emission from converter steelmaking processes. Environ. Sci. Pollut. R. 21, 7361-7368.

Li, S., Liu, G., Zheng, M., Liu, W., Wang, M., Xiao, K., et al., 2015. Comparison of the contributions of polychlorinated dibenzo-p-dioxins and dibenzofurans and other unintentionally produced persistent organic pollutants to the total toxic equivalents in air of steel plant areas. Chemosphere 126, 73-77.

Liu, G.R., Zheng, M.H., 2013. Perspective on the inclusion of polychlorinated naphthalenes as a candidate pop in annex c of the Stockholm Convention. Environ. Sci. Technol. 47, 8093-8094.

Liu, G.R., Zheng, M.H., Liu, W.B., Wang, C.Z., Zhang, B., Gao, L.R., et al., 2009. Atmospheric emission of PCDD/Fs, PCBs, hexachlorobenzene, and pentachlorobenzene from the coking industry. Environ. Sci. Technol. 43, 9196-9201.

Liu, G.R., Zheng, M.H., Lv, P., Liu, W.B., Wang, C.Z., Zhang, B., et al., 2010. Estimation and characterization of polychlorinated naphthalene emission from coking industries. Environ. Sci. Technol. 44, 8156-8161.

Liu, G.R., Zheng, M.H., Du, B., Nie, Z.Q., Zhang, B., Liu, W.B., et al., 2012. Atmospheric emission of polychlorinated naphthalenes from iron ore sintering processes. Chemosphere 89, 467-472.

Liu, G.R., Zheng, M.H., Nie, Z.Q., Cai, M.W., Zhang, B., Liu, W.B., et al., 2013a. Atmospheric emission of polychlorinated biphenyls from multiple industrial thermal processes. Chemosphere 90, 2453-2460.

Liu, G.R., Zheng, M.H., Cai, Z.W., Wu, Y.N., Jiang, G.B., 2013b. Dioxin analysis in China. TrAC-Trend. Anal. Chem. 46, 178-188.

Liu, G.R., Zheng, M.H., Hu, J.C., Liu, W.B., Wang, M., Jiang, X.X., et al., 2013c. Correlation analysis of unintentional polychlorinated naphthalenes with polychlorinated dibenzo-p-dioxins and dibenzofurans produced during industrial processes. Chin. Sci. Bull. 58, 2657-2663.

Liu, G.R., Cai, Z.W., Zheng, M.H., 2014. Sources of unintentionally produced polychlorinated naphthalenes. Chemosphere 94, 1-12.

Liu, G.R., Cai, Z.W., Zheng, M.H., Jiang, X.X., Nie, Z.O., Wang, M., 2015a. Identification of indicator congeners and evaluation of emission pattern of polychlorinated naphthalenes in industrial stack gas emissions by statistical analyses. Chemosphere 118, 194-200.

Liu, G.R., Jiang, X.X., Wang, M., Dong, S.J., Zheng, M.H., 2015b. Comparison of PCDD/F levels and profiles in fly ash samples from multiple industrial thermal sources. Chemosphere 133, 68-74.
Mari, M., Nadal, M., Schuhmacher, M., Domingo, J.L., 2009. Exposure to heavy metals and PCDD/Fs by the population living in the vicinity of a hazardous waste landfill in Catalonia, Spain: health risk assessment. Environ. Int. 35, 1034-1039.

Noma, Y., Yamamoto, T., Sakai, S.I., 2004. Congener-specific composition of polychlorinated naphthalenes, coplanar PCBs, dibenzo-p-dioxins, and dibenzofurans in the halowax series. Environ. Sci. Technol. 38, 1675-1680.

Nouwen, J., Cornelis, C., De Fre, R., Wevers, M., Viaene, P., Mensink, C., et al., 2001. Health risk assessment of dioxin emissions from municipal waste incinerators: the Neerlandquarter (Wilrijk, Belgium). Chemosphere 43, 909-923.

Pandelova, M., Lenoir, D., Schramm, K.W., 2006. Correlation between PCDD/F, PCB and $\mathrm{PCBz}$ in coal/waste combustion. Influence of various inhibitors. Chemosphere 62, 1196-1205.

Park, H., Kang, J.H., Baek, S.Y., Chang, Y.S., 2010. Relative importance of polychlorinated naphthalenes compared to dioxins, and polychlorinated biphenyls in human serum from Korea: contribution to TEQs and potential sources. Environ. Pollut. 158, $1420-1427$.

Rocha, D.A., Torres, J.P., Reichel, K., Novotny, E.H., Estrella, L.F., Medeiros, R.O., Netto, A.D. 2016. Determination of polychlorinated dibenzo-p-dioxins and dibenzofurans (PCDD/Fs) in Brazilian cow milk. Sci. Total Environ. 572, 177-184.

Saravia, J., Lee, G.I., Lomnicki, S., Dellinger, B., Cormier, S.A., 2013. Particulate matter containing environmentally persistent free radicals and adverse infant respiratory health effects: a review. J. Biochem. Mol. Toxicol. 27, 56-68.

Schifano, P., Lallo, A., Asta, F., Sario, M.D., Davoli, M., Michelozzi, P., 2013. Effect of ambient temperature and air pollutants on the risk of preterm birth, Rome 2001-2010. Environ. Int. $61,77-87$

Shih, T.S., Lee, W.J., Shih, M., Chen, Y.C., Huang, S.L., Wang, L.C., et al., 2008. Exposure and health-risk assessment of polychlorinated dibenzo-p-dioxins and dibenzofurans (PCDD/Fs) for sinter plant workers. Environ. Int. 34, 102-107.

Sun, J., Tang, J., Chen, Z., Nie, J., Zhang, S., Li, J., 2016. PCDD/Fs profile in ambient air of different types factories and human health risk assessment in Suzhou of Jiangsu province, China. Atmos. Pollut. Res. http://dx.doi.org/10.1016/j.apr.2016.07.010.

Tian, Y., Nie, Z., Tian, S., Liu, F., He, J., Yang, Y., et al., 2015. Passive air sampling for determining the levels of ambient PCDD/Fs and their seasonal and spatial variations and inhalation risk in Shanghai. China. Environ. Sci. Pollut. R. 22, 13243-13250.

Trnovec, T., Jusko, T.A., Sovcikova, E., Lancz, K., Chovancova, J., Patayova, H., et al., 2013. Relative effect potency estimates of dioxin-like activity for dioxins, furans, and dioxin-like PCBs in adults based on two thyroid outcomes. Environ. Health Perspect. 121, 886-892.

USEPA. Regional screening levels (RSLs) - generic tables, https://semspub.Epa.Gov/work/ 03/2229063.Pdf (May 2016).

Van den Berg, M., Birnbaum, L.S., Denison, M., De Vito, M., Farland, W., Feeley, M., et al. 2006. The 2005 World Health Organization reevaluation of human and mammalian toxic equivalency factors for dioxins and dioxin-like compounds. Toxicol. Sci. 93, 223-241.

Villeneuve, D.L., Kannan, K., Khim, J.S., Falandysz, J., Nikiforov, V.A., Blankenship, A.L., et al. 2000. Relative potencies of individual polychlorinated naphthalenes to induce dioxin-like responses in fish and mammalian in vitro bioassays. Arch. Environ. Contam. Toxicol. 39, 273-281.

Wang, L., Weng, S., Wen, S., Shi, T., Sun, G., Zeng, Y., et al., 2013. Polychlorinated dibenzop-dioxins and dibenzofurans and their association with cancer mortality among workers in one automobile foundry factory. Sci. Total Environ. 443, 104-111.

Warner, M., Eskenazi, B., Samuels, S., Needham, L., Brambilla, P., Mocarelli, P., 2011a. Serum dioxin concentrations and breast cancer risk in the Seveso women. Epidemiology 22, S102.

Warner, M., Mocarelli, P., Samuels, S., Needham, L., Brambilla, P., Eskenazi, B., 2011b. Dioxin exposure and cancer risk in the Seveso women's health study. Environ. Health Perspect. 119, 1700-1705.

Weber, R., Iino, F., Imagawa, T., Takeuchi, M., Sakurai, T., Sadakata, M., 2001. Formation of PCDF, PCDD, PCB, and PCN in de novo synthesis from PAH: mechanistic aspects and correlation to fluidized bed incinerators. Chemosphere 44, 1429-1438.

WHO, 1998. Assessment of the Health Risk of Dioxins: Reevaluation of the Tolerable Daily Intake (TDI); WHO Consultation. WHO European Centre for Environment and Health International Programme on Chemical Safety, Geneva:p. 1998. http://www.who.int/ ipcs/publications/en/exe-sum-final.pdf.

Yu, L., Mai, B., Meng, X., Bi, X., Sheng, G., Fu, J., et al., 2006. Particle-bound polychlorinated dibenzo-p-dioxins and dibenzofurans in the atmosphere of Guangzhou, China. Atmos. Environ. 40, 96-108.

Zhao, G.F., Wang, Z.J., Zhou, H.D., Zhao, Q., 2009. Burdens of PBBs, PBDEs, and PCBs in tissues of the cancer patients in the e-waste disassembly sites in Zhejiang, China. Sci. Total Environ. 407, 4831-4837. 